\title{
Using Short Texts to Teach English as Second Language: An Integrated Approach
}

\author{
Jane Kembo \\ Department of Applied Linguistics, Rongo University, Kenya
}

Copyright $(\mathrm{C} 2016$ by authors, all rights reserved. Authors agree that this article remains permanently open access under the terms of the Creative Commons Attribution License 4.0 International License

\begin{abstract}
The teacher of English Language is often hard pressed to find interesting and authentic ways to present language to target second language speakers. While language can be taught and learned, part of it must be acquired and short texts provide powerful tools for doing so and reinforcing what has been taught/learned. This paper starts from research, but utilizes the studies and experience to present a way of integrating language skills through the use of short texts. Short texts provide opportunity to focus on detail on aspects of reading (nominal and pronominals, direct references, allusion, imagery, inference making, use of schemata), listening and speaking, vocabulary, grammar and even writing skills in ways that a full length text may not. In addition, short texts give weak language learners a sense of fulfillment as readers, instead of the frustration of reading long texts without comprehension. The paper will utilize four short texts to demonstrate to teachers how they can enable their learners to develop different skills of/in English as the target language. The texts and approaches are versatile, and depending on tasks could be used with any students SL learners of high school, or even university, as long as tasks are set at the right cognitive and literary levels. The methods discussed here could also be used with other languages.
\end{abstract}

Keywords Short Texts, Teaching, Integrated Approach, Reading, Second Language

\section{Introduction}

The paper is aimed at demonstrating how the teacher of reading can weave other skills and areas of language into the reading lesson to enable learners to perceive language from a holistic point of view, and disabuse them of the notion that all meaning is in the text. While the paper uses research to make some of its arguments, it is also borne out of years of experimentation and practice in teaching English as a Second Language. The paper argues that while there is a place to utilize longer texts in the reading class, short texts give opportunity for in-depth analysis and activities that enrich both the students' reading abilities and language experience. Reading in a second language calls for fast, automatic word decoding and access to the mental lexicon (dictionary); this means working on building speed and fluency and on learning to recognize at least 10,000 words in the new language. Learners can build speed and fluency by learning to recognize at least 10,000 words in the new language....Walter (1) argues that by utilizing short prose passages, poetry, students' own writing, and extracts from other subjects the teacher can hone both reading, language skills and knowledge.

Using reading as a stepping stone to language teaching and learning is not only an important means of ensuring that learners become better readers but also meet both new and old language items in contexts that make them authentic and re-inforce what has been learned.

The activities of the paper are aimed at high school learners who will increasingly need to do work for themselves and access information with understanding at more challenging levels. The activities are adaptable to different level of learning, but his calls for thorough preparation on the part of the teacher.

\subsection{Some Research Evidence and Background}

Chikalanga,8[2] and Kembo, [3] state that most learners go through school without ever acquiring effective reading skills to enable them to understand texts adequately. Lubelska [3] states that learners have 'difficulty in making sense of texts they want to read' (p. 569). It is interesting that as central as reading is, it is only formally taught from primary 1 to 3 . After this, observations show (Kembo,[4]; Roy-Campbell and Quorro [5] observing SL situations in Tanzania, and Lunzer [6] doing so in a British context, found that there is little teaching of reading as a skill. The same situation obtains today as witnessed by the number of students who come to the university hardly able to fill in forms or follow assigned texts, or instructions effectively in examinations. Exam results (KNEC,[7], 2012 [8], Ethiopia, 2011[9]) discuss the following as weaknesses that prevent learners from passing in national examinations: 
Lack of language to:

- Understand concepts adequately

- Failure to read questions with understanding

- Lack of language to express what they know, especially in open ended questions, when they are assumed to understand the questions.

The SACMEQ survey [10] done from 2006 to 2010 of Grade 6 pupils on reading, Math, and health that covered the following 15 countries in the African continent: Botswana, Kenya, Lesotho, Malawi, Mauritius, Mozambique, Namibia, Seychelles, South Africa, Swaziland, Tanzania, Uganda, Zambia, Zanzibar, Zimbabwe. The study found that most pupils were scoring below the expectation for their class stage.

However, observations of language classes, show that teachers of language, who are supposed to teach reading, often approach it with a view that it is 'acquired' and therefore, not necessary to teach after primary three (Roy-Campbell and Quorro, [11]; Lunzer and Gardner, [12]). At any rate, many teachers are not fully prepared to teach reading effectively as a skill, let alone one that is central to schooling.

Apart from knowledge and skills, the teacher of English Language is often hard pressed to find interesting and authentic ways to present language to target second language speakers. Besides 'dry' textbook material, 'poor' teacher pre-training, teachers often fall back on the text book to cover pedagogical deficiencies and tend to use 'read the passage and answer the questions on it' approach. While language can be taught, part of it must be acquired and contexts used for reading provide powerful tools for doing so. In this paper, I describe the use of short texts as an approach to improving comprehension and other skills for second language learners.

\subsection{Why Short Texts?}

Having been a teacher of reading and communication for over 20 years, I believe that short texts provide opportunity to focus on detail in aspects of reading (nominal and pronominals, direct references and, allusion, imagery, inference making, use of schemata), listening, vocabulary, aspects of grammar (tenses, reported speech, intonation, even writing skills in ways that a full length text may not, because of the time it takes learners to get through and the questions that may accompany them. In reading, as in any other skill, practice hones the ability of learners to: comprehend, see connections, analyze, compare, use literary and linguistic skills to deconstruct texts. In addition, short texts give, especially the weak language learners, a sense of fulfillment and achievement as readers, instead of the frustration of reading long texts without comprehension.

The paper is aimed at demonstrating how the teacher of language can weave other skills into reading and areas of language into the reading lesson to enable learners see it from a holistic point of view and disabuse them of the notion that all meaning is in the text. The paper will demonstrate that while there is a place to utilize longer texts in the reading class, short texts give opportunity for in-depth analysis and activities that enrich students' language experience.

\subsection{Short Texts for Intensive Reading}

Reading is a powerful window into the world: science, arts and other people's lives and interactions with others and the forces around them. It enables an effective reader to transport him/herself to other worlds and vicariously 'experience' another life or other lives. Reading Alice in Wonderland transports one from the mundane to the fantasy world where extraordinary things take place. However, before any reader does this, they must unlock both the surface (literal) and inferential (sub-surface) or non-literal meanings of any text before them.

The reading skill also permeates each subject covered in school or even outside it. Inside school, learners must be able to read and interpret instructions, notes, and examination questions appropriately (Bryant and Bradley [12]). They must understand what each task requires of them to be successful. Outside school people must read a plethora of articles of different lengths and importance such as forms, newspapers, bills, prescriptions, manuals for different appliances, instructions and directions in public places. Therefore, reading is one key skill that may enable one to live a full life in the current world. Observation and research show that a lot of students leave school without being able to read effectively beyond the surface (literal) level (Chikalanga, 1991[13], Kembo, 1994 [14], Kembo, 2016 [15]).

At one level, the reader must learn to read word by word quickly enough and build meanings progressively so that both connotative and denotative meanings of a text are accessed successfully. How the reader does this takes both learning and acquisition through training and practice.

The teaching of reading mainly assumes that learner reading is something that learners acquire, in the technical sense, as they read. While this may be partly true, because it is a skill, it is also true that learners must be shown how to unlock meanings in texts. Because reading is a skill, the metacognitive skills for successful reconstruction of meaning need to be engaged successfully. In other words, as a skill room needs to be made for both practice and learning of the principles. It is in this connection that teachers of reading and language need to find interesting ways so that the four skills of language can be utilized to enrich each other.

Short texts lend themselves particularly well to the teaching of intensive reading using an integrated approach:

- They will tend to give a sense of completeness especially if properly chosen by the teacher

- They can be successfully read through by even weak students, thus providing a sense of achievement which learners require to build confidence in their ability 
- The teacher can easily build into the lesson other language skills of speaking, writing vocabulary and areas of grammar and literature that have been learned. This will reinforce the lessons learned elsewhere enabling learners to see language and literature as a continuum rather than as compartmentalized subjects.

- It is a lot easier to teach discrete reading skills through a short passage that is perhaps a few paragraphs only than two pages of reading that weak students are struggling with.

- When texts from other content area are utilized learners will begin seeing learning and reading as holistic and the latter as a skill that is transferable to longer texts and other content areas.

The argument here is not that the teacher of reading in a SL should not use longer texts. The thesis is that while there is a place for the reading these long texts as a particular skill, the more refined sub-skills of reading such as analysis, language, vocabulary, inferencing at various levels can be taught successfully using shorter texts to prepare learners for reading longer texts.

In the sections below, I illustrate how this can be done using four short texts of varying lengths.

\section{Illustration Text 1}

1. Ashen-faced, Harry clutched his chest.

2. Thirty minutes later the stethoscope did not register a heartbeat.

\section{Questions}

What inferences can we make from sentence 1 ?

- That Harry is in shock, (ashen faced)

- That he is in pain (clutched)

- That he refers to the same he i.e. that he clutched 'clutched his own chest'.

Sentence (2) suggests the following:

- That a nurse or doctor has been called in, or

- That he has been rushed to hospital/health institution (signaled by the stethoscope)

- That either of the two actions above has been done by someone else

- That some kind of examination has taken place (signal- stethoscope)

- The time lapse between proposition 1 and 2 is thirty minutes (thirty minutes later)

- That the Harry is already dead. (the stethoscope did not find a heartbeat).

Other questions that the teacher can use:

- What do the words below mean in the sentences in which they are used?

- Ashen-faced
- Clutched

- Register

- Look at the passage above:

- Identify the subject and verb clause of each sentence

- What voice is the text using? Why?

- Turn the sentences into First Person speech.

- Imagine you are the doctor:

- Write down the statement you would make from the second sentence.

- Read that statement aloud to a family member.

\section{Illustration Text II}

\section{Onguro and his father}

At fifteen years of age, Onguro felt the pain and shame of disappointment and being let down by a father who had been his hero all his life. He was fifteen years of age.

He was the only kid in the village who had shop-bought toys of all kinds and that brought him many friends. His age mates in the village made theirs using grass, bits of old clothes, newspapers and polythene. His family had things that were only found in houses in town in homes where people were relatively well off.

How his father came by these beautiful things he did not know, but he had always looked up to him and wanted to be like him when he grew up. He did not know what he did or where he worked until one day he found groups of villagers, and even his playmates agitated and shouting. Everyone seemed to be carrying a stone or stick.

In the middle of the crowd a man was lying face upward, having been beaten to death. They claimed he had been caught red handed in the night trying to enter a widow's house. As he slunk away covered in shame and confusion, he wondered whether the villagers were wrong. Part of him knew that it was probably true. How would he face the world after this? He felt double pain grip his heart. He could not even cry. Jane Kembo (C 2015)

Using the above text the teacher can prepare the following possible tasks that can be done by different grades. Please note that these tasks may not be the only ones that can be done. At the same time, no single lesson can accommodate all the tasks. Class organization, which we discuss later is one way of accomplishing as many as possible of the related comprehension and language activities.

\section{Comprehension Questions}

\section{Section A: literal questions}

i. Who are the two main characters in the story?

ii. What did Onguro's father buy him?

iii. How did Onguro's father buy the nice things for his family?

iv. What finally happened to the father?

v. How long had Onguro's father been his hero? 


\section{Section B: Comprehension}

i. Why was Onguro's father his hero?

ii. What did he do for a living? How do you know?

iii. What finally happened to the father? Give evidence from the passage.

iv. Why do you think Onguro felt "pain and disappointment? With whom was he disappointed?

v. Why does the author use the word 'brought' when talking about Onguro's friends? What does he mean?

vi. What was special about Onguro's family?

\section{Section C: Further literary work}

i. What themes does the writer deal with in the short passage?

ii. Using the story to support your argument, explain why the author describes the pain Onguro felt as 'double pain'.

iii. "Part of him knew that it was probably true." (paragraph 4 line 4). What was probably true? Why does the author use the word 'probably'?

iv. What is the irony in the story?

v. By the end of the story, do you think Onguro would still want to be like his father? Give reasons for your answer.

\section{Section D: Vocabulary Questions}

Give words and expressions that have similar meanings to the following words and expressions as used in the passage above:

i. Let down

ii. Hero

iii. Looked up to

iv. Agitated

v. Well off

vi. Caught red handed

vii. Slunk away

viii. Grip

\section{Section E: Vocabulary and language}

After explaining the meanings of the words above as they are used in context, make one sentence with each word or expression in a way that makes the meaning obvious. You will write a total of eight (8) sentences.

\section{F. Reference questions}

Look at the passage again. What/ who do the words below refer to?

i. $\quad H e$ in line 1 paragraph 3 ii. $\quad$ Him in line 2 paragraph 3

iii. $\quad H e$ in line 2 paragraph 4

iv. $\quad 2^{\text {nd }}$ he in line 2 paragraph 4

Section G: Introduction to the use and learning of Phrasal verbs:

a. What do you think the phrases below mean?

b. Use them in sentences of your own that make their meaning obvious to the reader.

i. Let down

ii. Looked up to

\section{Section H: Introduction to Idioms}

a. What do you think, the phrase below means?

iii. Caught red handed

\section{Section I: Writing:}

Take one of the themes and write:

i. A Two Stanza poem on it

ii. Two paragraphs on it.

\section{Section J: Speaking (Debate)}

'What the villagers did to Onguro's father was not right?'

i. Argue for or against, supporting your reasons.

ii. Let the learners recite one of the poems they have written.

iii. You could also have learners prepare a short drama based on the story.

\section{Illustration Text III}

\section{READ THE PASSAGE BELOW AND ANSWER THE QUESTIONS THAT FOLLOW FATE?}

Maria was a beautiful girl who, for most of her life, did not know her father. He had died while she was too young to remember the details. Even his face had receded from her active memory. The one thing she could remember, though, was that her father had carried her in a car to visit friends and go to interesting places. She remembered that he had valued her and called her 'precious'. In fact, while he was alive, precious had been her name as much as Maria. That seemed like another life.

She did not understand where the car had gone after he died. Nor did she vaguely understand what had happened to the little box (TV) that had entertained her until a male uncle had come to claim it.

When she reached 16 years and her mother could not pay her school fees, she had been asked to go and work for $\mathrm{Mr}$ Kafiri. Mr Kafiri had lost his wife and was living all alone. 
The promise of wealth and stability, and the promise of providing for her mother and siblings made her agree to wifely duties in her new station.

When Mr Kafiri died two years later, she was too young and too strong to think she would be next. Jane Kembo (C) 2014)

\section{Questions}

\section{Preparation or Pre-reading Questions:}

What preparation questions/activities would you use to help your learners be mentally or cognitively prepared for the study of the short text above.

\section{Literal or Textual Level}

1. What happened to her father?

2. Why did her mother ask her to go and work for Mr. Kafiri

3. What did Maria remember about her father?

4. What had happened to their car and TV?

5. What name did her father call her?

\section{Comprehension Questions}

5. What kind of girl was Maria?

6. From the passage, how old, do you think she was when her father died?

4. What was her relationship with her father?

5. With evidence from the passage, describe the kind of life Maria's family led after her father's death.

\section{Reasoning and Analytical Questions}

6. Why did she not know her father?

7. 'It seemed like another life. What do these words mean?'

8. How many people died in this story? Name them and support your answer.

9. 'She did not imagine that she would be next'. From this, what happened to Maria?

10. What was it that three people succumbed to?

11. Identify the topics (subjects/themes) covered in this short story?

\section{Evaluative Questions}

12.

a. What price did Maria pay for agreeing to wifely duties?

b. What literary device does the author use here?

13. Why, do you think, the writer has given the man in the story the name Mr Kafiri?

14. What had Mr. Kafiri done to Maria? Was he right or not? Support your answer with at least two reasons.

15. How does the author use language to discuss the issues is the story?

\section{Language Questions}

Pronominal references

What do the following words refer to in the text above?

i. he (line 1)

ii. It (line 3) iii. It (line 3 para 2)

\section{Vocabulary Questions}

Use other words that nearly mean the same as the following:

i. $\quad$ Valued

ii. Precious

iii. Wifely duties

\section{Illustration Text IV}

\section{Read the following passage and answer the questions that follow}

Mount Penyo forms an idealic scene against the sky. Its rich blue and greenery, thick against the horizon, everywhere you look, is breathtaking. Dotted with human settlement and farms of various kinds, it looks beautiful against the sky to any first time visitor. The people around it, though, often do not think about its beauty, but they appreciate its fertility which derives from the volcanic soils they use for farming.

The mountain is thirty thousand feet high. The climate on Mt. Penyo is variable. On the higher slopes it is too cold for much agricultural activity. Mt Penyo receives rain at least ten months of the year. Being near the equator it is also a place with warm as well as chilly weather.

The Burkas and Bongolas live on the slopes of the mountain. While the Bongolas live on the East side of the mountain, the Burkas do so on the West. The Bongolas practice mainly animal rearing, keeping cattle for both beef and meat, goats, sheep and even lately, pigs. Many households of both Bongolas and Burkas keep chicken for domestic consumption, although this has recently become commercial due rising demand from the local Feno town that has sprung up between the two communities.

The Bongolas supplement natural cattle feed with napier which they grow in strips in homes. But they also buy maize, millet and wheat stalks which the Burkas grow on the slopes and the lowlands of the area. The Burkas, the farming stay of the mountain, in addition, grow a variety of crops. These include a variety of beans, potatoes, sugarcane and bananas on the warm lowlands, along the many streams and rivers in the area. Cropping of appropriate crops is done as high as four thousand feet on the mountain. On slopes higher than 4,000 ft., they grow coffee and tea. Between 4, 000ft and 6,000 both communities have developed the mining of conflue, a mineral that is useful in reinforcing walls. When mixed with cement, it protects walls against cracks, and is an insect repellant. (Kembo (C) 2015)

\section{Now answer the questions on the passage above}

1. What, according to the passage, is conflue?

2. Name the groups of people that live on the mountain 
slopes and lowlands.

3. What makes it easy to do farming in the passage?

4. Why are coffee and tea, rather than beans, grown higher up in the slopes?

5. What unites the two groups of people in the passage? Give reasons.

6. Why do you think chicken are no longer just kept for domestic consumption?

7. Where do the two local communities buy supplies from?

8. Why, do you think, the people who live on the slopes of mountain appreciate its soils but not its beauty, while visitors do?

9. Do you think the houses of the communities in the passage are infested with termites? Why or why not.

10. Explain the meanings of the following words and expressions as used in the passage:
a. Breathtaking
b. Variable
c. Appreciate
d. Commercial
e. Farming stay

11. With evidence form the passage, how was Mt Penyo formed?

12. Looking at the language of the passage what is the writer's style? Give reasons for your answer.

13. Draw a diagram that will summarize the information on Penyo from the Passage above, plotting all the information appropriately.

14. Draw a table of Mount Penyo and plot the activities of the communities that live on it.

The passage above and activities on it can be used to enrich language, but also buttress learning in other subjects such as Geography. In using other texts for the language class the teacher will demonstrate that the skills learned in the language class are not isolated to language but can be transferred and vice versa.

\section{Discussion}

In the passages above, I have shown how short passages can be utilized by the teacher of English as a Second Language to teach language and to hone learners' abilities to:

The ability to unlock both literal (surface) enables a reader in the next step to open up metaphorical (hidden) meanings in a reading passage. If a reader has not understood this surface meaning, it almost impossible to make appropriate inferences of any kind. The reader, thus must understand the individual lexical meanings, weave this quickly into a whole and comprehend, first, literal and then metaphorical meanings.

There is ample evidence that reading not only strengthens second language vocabulary, but also expands it as readers meet words, or the same word in different contexts. After all, that is the way lexical vocabulary is acquired in real life is through hearing it in our L1s. Apart from learning vocabulary, learners also learn new structures, which can form a strong scaffolding both for learning of new structures, and introducing grammatical items to a class.

In listening to each other read, discuss points in groups, debate, or answers and their rationale, second language learners will sharpen both listening and speaking skills

- In using reading contexts to practice rewriting passages either as poems, prose from poems, reported speech form .

- Learn to follow back and forward references in a story or text

As learners feel a sense of achievement with short texts confidence in their ability as readers of the language of instruction creates intrinsic motivation as the ability as readers I unlocked.

\subsection{Teacher Preparation for the Use of Short Texts}

For the teacher to prepare the kind of texts we have used above for demonstration calls for some of the following: first:

- Creativity - being able to use techniques that are not routine and observing how they work in the reading classroom.

- Variety -exposing pupils to a variety of texts including: from content text books, learners' writing, teachers' writing, magazine articles, jokes, anecdotes etc.

- Ability to create/or identify texts that can be used besides the English Text book.

Second, the teacher can create a repertoire of texts and tasks at different levels of difficulty and challenge that can be used with learners in different class levels. In the view of the author, any text can be used at different levels of learning; it is the tasks that are set on them that determine the level of engagement and challenge. In doing this, the teacher:

- Must read the material thoroughly at preparation to:

- Identify before-reading and after-reading exercises can be incorporated into the lesson to help learners engage with a particular text.

- Determine what activities are possible with the material they have identified

- Decide on what language aspects can be focused on

- Select, beforehand, what classroom interactions and organization will enable learners to benefit maximally from the lesson

- Define, before actual teaching, how to assess individual/group understanding and interpretation of a given text and tasks.

Third, identify how a given text can act as a stepping stone to other activities, such as drama and poetry writing, for example. 
Fourth, the teacher needs to look at the text and prepare tasks that will engage pupils in pre- reading activities that may include brain storming, drama, question and answer or even reflection. These mental warm-up exercises enable learners provide scaffolding by enabling learners to:

- Relate relevant life experiences (world knowledge, appropriate schemata ) to what they are about to read

- Access the knowledge that they have and learn that all meaning is not always in the text

Further it enables the teacher to assess gaps that may be there in learner knowledge required for understanding the text so that he/she can fill in what is necessary.

The teacher requires, at preparation, to come up with tasks at different cognitive levels: recall (textual information), comprehension, analysis, synthesis, evaluation, language, literary and other skills (drawing, modelling, painting), drama, which enable learners to deepen learning/reinforcement and reactions using the context of given texts. The use of drama, in particular will enable learners as readers to bring their own deconstruction and interpretation of meaning into the text as groups, and to learn to negotiate with one another. It will further enable them to practice language already learned and presentation that is accompanied by extra-lingual features (intonation, facial, gestures and other body language). Preparation for some of the activities can be carried out by learners outside class and presented during lessons.

\subsection{Actual Presentation of Short Texts}

\subsubsection{Introductions}

The teacher needs to have a pre-reading warm up for most of reading lessons. This mentally builds anticipation and heightens curiosity and therefore, makes learners want to read for themselves. Introductions should be focused and not eat too much into the main part of the lesson. They should also be brief and creative, varying stimuli to keep students interested. In one instance set induction can be used, in another, a story, another, short questions, another, a brainstorming exercise etc.

\subsubsection{Reading stage}

One of the cardinal rules for reading classes is that each learner requires to read the text for him/herself. Schools and language teachers should try, if they can, where possible to have each learner have a copy of the text being read. If this cannot be done only two students can share a text; the reason being that every reader does his/her reading at own pace and focuses on different things from a text. On the other hand, teaching reading is one that helps and enables learners to learn to focus on what is important, depending on what their aim for reading is.

Sometimes, a teacher will actually time reading to enable learners build speed which has been identified as a skill necessary for efficient processing of textual information. Ideally learners should read a given text at least twice, but this will depend on the focus of the lesson.

\subsubsection{Post Reading Activities}

Questions and tasks can be used to teach various areas of language in the context of a text. Similarly what is learned from the text can be used to introduce new areas of language e.g. reported speech, turning reported speech into direct speech, intonation, tenses, pronunciation, synonyms and antonyms, among many other language activities. Teaching language skills in the context in a text performs several functions:

i. Reinforces rules and language already learned

ii. Shows learners how subjects and areas of language are connected

iii. Expands vocabulary

iv. Demonstrates how words can be used creatively in different contexts. This is important for Second Language speakers, who will not always have access to this around them

v. Helps students vicariously experience what they would not do outside the reading class

vi. Sensitizes them and hones skills for identifying what is logical and appropriate interpretations as they deconstruct texts

vii. Sharpens the skills of comprehension, analysis and evaluation.

viii. Strengthens their overall language ability and reinforces their literary skills.

ix. Increases their confidence as learners through a sense of achievement in the variety of activities that the teacher plans for each reading text.

x. Gives learners stepping stones that they can transfer to longer texts and other content areas.

xi. Enables the teacher to expose his/her learners to a variety of genres and texts for study purposes, including from subjects that they study in school in new context even as language across the curriculum becomes a practice in the language classroom.

\subsection{Class Organization for Reading Activities and Language Tasks}

The utilization of different classroom structures for language learning serve different purposes. For example, individual work allows each learner to read the text for his/herself and enables assignments and task to be done quickly. In addition, the teacher can assess individual abilities.

When learners are allowed to work in pairs through Think- Pair-Share, they are enabled to develop listening, negotiation and language skills. . As they do this, they negotiate the best possible responses with each other and give reasons, practice language they have learned or acquired. Working in pairs is less intimidating than working in groups and so opens ways for even the timid 
students to interact with each other as they learn.

When Small Group Work is utilized, the teacher, in preparation, must determine which tasks on a given text should be done by small groups for maximum benefit. Small groups should range between five and seven members; this allows all members to take active part in the learning tasks and to contribute. Drama, for example, lends itself, very well to small group work. Evaluative questions and synthesizing questions can also be done well in groups, but so can other tasks that stem from reading. Debates and points for arguing against or for a topic or position can be done by a group and presented by a nominee of the group. Using group work has advantages that go beyond the subject:

- Learners get to cooperate with one another instead of competing

- They learn from each other

- They use language they have learned

- They get to boost their own self confidence and speaking with others, especially if the teacher makes sure that the groups are small and all of them participate in the tasks given.

- They learn to listen to others, negotiate and reason out why they think their stand/understanding is appropriate for a particular task or prompt.

One of the ways a teacher can organize the class for post reading activities using the example of tasks based on Illustration Text IV above could be to divide the class as indicated below:

$\begin{array}{llr}\text { i. } & \text { Grammar and vocabulary } & \text { Group 1 } \\ \text { ii. } & \text { Literary skills } & \text { Group 2 } \\ \text { iii. } & \text { Writing } & \text { Group 3 } \\ \text { iv. } & \text { Listening and Speaking } & \text { Group 4 } \\ \text { v. } & \text { Use one of the themes to write two short } \\ & \text { stanzas of poetry. } & \text { Group 5. }\end{array}$

As stated before, short texts give learners a sense of achievement as they can finish reading them, even for those that are strugglers in SL reading and language. In addition, the learners and the teacher can do more with a short text in any one lesson than they can with a much longer text. They are also ideal in studying various nuances of language in context. The teacher of language can design many different activities as shown above by careful planning and preparation before class. Furthermore, learners can work as individuals, in pairs or in groups on some of the tasks set by the teacher, thus varying class interaction. The writing of students, where they can turn prose into poetry and vice versa, can be used to further their individual, group interaction, with a given reading text. Using the text for loud reading, when there are interesting aspects of speech, tone and attitude make short texts ideal for brief practice in the language classroom.

Besides, using drama to actualize the experience of the text is one way of letting a class of learners act out their understanding and interpretations of a given text.

Studies in the L2 contexts have also investigated how the use and effectiveness of specific knowledge sources depends on learner characteristics, such as L2 proficiency (Bengeleil \& Paribakht, 2004[16]; Haastrup, 1991[17], 2008[18]), vocabulary knowledge (Nassaji, 2006 [19]; Wesche \& Paribakht, 2010 [20]), and background knowledge (Pulido, 2007[21]). In using different texts, the teacher will be widening the background knowledge, vocabulary breadth of learners and their meaning construction skills.

\subsection{Sources of Reading Texts}

For the teacher who is keen on excellence, there are a numerous sources of materials for the skills of language: newspapers and magazine articles, comic strips, stories, poems, adverts, books of other subjects (geography, chemistry, history, religion, etc). In addition, the learners' and teacher's own writing can be used for classroom reading. Other sources such as written songs can form part of practice material that a teacher can use.

\subsection{Required Teacher Skills}

To be able to perform the above activities effectively requires certain skills. I call them skills because they will improve with time and practice. The teacher needs to be able to take risks with experimenting with writing own texts and developing an eye for potential material that can be used with their classes: newspaper and magazine articles, poems, jokes, good compositions from his own class, textbooks extracts, group writing assignment products. What I am advocating is that the teacher of reading and language must be a voracious reader.

In the second group of skills the teacher needs to develop ability for preparing tasks at various levels and keep them in folios; these can be revised from time to time. Doing this takes practice. In this group also belong the practice for developing a repertoire of questions at varying cognitive levels, depending on the classes being taught. One text can be used, as stated before, for different classes; the tasks, however, will vary by ability of the various stages of study such as secondary $1,2,3$ or 4 , or university.

Ability to organize work in groups without wasting time is one that will grow if learners enjoy what they are doing, but also feel that they are learning useful skills. Noise in the classroom will have to be controlled but the teacher needs not fear it, especially when learners work in groups. Productive but controlled noise will be tolerated; the teacher, however, must ensure that it does not unduly disturb other classes in the school.

The teacher requires to participate in some of the activities with the pupils. This will enable him to model such things as intonation, pronunciation. By, for example, joining the class in a short drama, learners may be encouraged to try new things without being too self-conscious. Although this adds to the teacher's vulnerability, it is good for creating rapport with learners. 


\section{Conclusions}

This paper set out to discuss the benefits of using short texts and how to use them to train learners in varied language and literary skills among those who read and learn English language as a Second Language. As Hudson,(2007[22]) points out there is "no magic bullet, no single explanation for what teachers can do to ensure that their students learn to read a second or foreign language." Practice and plenty of it may be the only way out. I must end, though, by stating that while longer texts are useful, they should be left until learners have developed adequate confidence, skills and strategies for text deconstruction and could be introduced incrementally. Incremental range of difficulty in both texts and tasks should be managed so as to challenge learners without causing undue frustration.

Reading is hard, but can be made easier if teachers provide some background, where this is required. In addition, variety of texts and activities keeps both interest and learning alive. Meaningful extensions of the reading class can incorporate skills required in other content areas such as drawing and labeling, painting, and games can be incorporated into the lessons. The list is endless and teachers can only get better through practice.

\section{REFERENCES}

[1] Walter C. H. (2012). First to Second Language Reading Comprehension. International Journal of Applied Linguistics. 2007. Wiley.

[2] Chikalanga, I. (1991). Inferencing in reading: A cross-cultural study. Unpublished $\mathrm{PhD}$ Thesis. University of Reading.

[3] Kembo, J. (1997). Inferencing in a second Language. Unpublished $\mathrm{PhD}$ Thesis. University of Reading. UK.

[4] Lubelska, D (1991). An Approach to Teaching Cohesion to Improve Reading. Reading in a Foreign Language, 7, 2, 569-598.

[5] Roy-Campbell, Z.M. and Quorro, M P. (1987). Survey of Reading Competence in English in secondary school students in Tanzania.

[6] Lunzer,E.and Gradner, K.(eds.) (1979). The effective use of reading. London: Heinemann.

[7] Kenya National Exams Council Report 2011.

[8] Kenya National Exams Council Report 2012.

[9] Ethiopia National Exams Council Report 2011.

[10] Roy-Campbell, Z.M. and Quorro, M P. (1987). Survey of Reading Competence in English in secondary school students in Tanzania.

[11] Lunzer,E.and Gradner, K.(eds.) (1979). The effective use of reading. London: Heinemann.

[12] Bryant, P. and Bradley, L. 1985. Children's reading problems - Psychology and education. Basil Blackwell.

[13] Chikalanga, I. (1991). Inferencing in reading: A cross-cultural study. Unpublished $\mathrm{PhD}$ Thesis. University of Reading.

[14] Kembo, J. (2016) The Challenge of Teaching English Language as second language. A paper presented at International Conference on Foreign Languages and Literatures 11-13 February, 2015 at Kenyatta University, Nairobi, Kenya.Conference Theme: Foreign Languages in Africa in the 21st Century: Opportunities and Challenges

[15] Bengeleil N. F and Paribakht, T.S (2004). L2 reading proficiency and lexical inferencing: An Investigation in the Iranian EFL learners: The Canadian Modern Language Review, 61,225-249.

[16] Haastrup, K. (2008). Lexical Inferencing procedures in two languages. In D. Albertechtsen, K. Haastrup, and B.Henriksen (Eds.) Vocabulary and Writing in a first and second language: processes and development, 67-111. New York: Pulgrave Macmillan.

[17] Nassaji, H. (2006). The relationship between depth of vocabulary knowledge and L2 learners' lexical inferencing strategy use and success. The Modern Language Journal, 90, $387-401$.

[18] Wesche, M. and Paribakht, T.S. (2010). Lexical Inferencing in a first and second language Cross-linguistic discussions, Clevedon, UK: Multilingual Matters.

[19] Pulido, D. (2007). The effects of topic familiarity and passage sight vocabulary on L2 lexical Inferencing and retention through reading. Applied linguistics, 28, 66-86.

[20] Hudson, T. (2007). Teaching Second Language Reading. Oxford University Press. ISBN. 978-0-19-42283-3. Inferencing and retention through reading. Applied Linguistics, 28, 66-86. 